\title{
Reflexiones sobre la distinción entre Derecho Público y Derecho Privado*
}

\section{Reflections on the distinction between Public Law and Private Law}

Eberhard Schmidt-Assmann"

El artículo delinea el marco conceptual de la distinción entre Derecho Público y Derecho Privado, para después abordar algunos problemas actuales concernientes a la utilización del Derecho Privado por parte de las administraciones públicas.

Palabras clave: Derecho Público; Derecho Privado; Libertad en derecho privado; Dualismo; Actividad Administrativa.
The article outlines the conceptual framework of the distinction between Public Law and Private Law, then addressing some current issues regarding the use of Private Law by public administrations.

Keywords: Public Law; Private Law; Freedom in private law; dualism; administrative activity.

\footnotetext{
* Publicado previamente en: Diritto Amministrativo, año XXV, Fasc. 4 (Milán, Giuffrè Editore) 2017, pp. 625-636. Traducción del italiano bajo el cuidado del prof. Alejandro Vergara Blanco.

** El prof. Eberhard Schmidt-Assmann (Celle, Alemania, 1938) es profesor emérito de Derecho público en la Universidad de Heidelberg, Alemania. Licenciado en Derecho y Filología clásica en las Universidades de Göttingen y de Ginebra y Doctor en Derecho por la Universidad de Göttingen y Doctor Honoris Causa por la Universidad de Atenas (Grecia); por la Universidad de Huelva (España) y por la Universidad La Sapienza, Roma (Italia). Miembro de la Academia de Berlín-Brandenburg de Ciencias y Humanidades. Entre su extensa obra, cabe destacar especialmente con motivo del presente trabajo traducido, Das allgemeine Verwaltungsrecht als Ordnungsidee (Springer, 1998), traducido en España como La teoría general del Derecho administrativo como sistema (INAP-Marcial Pons, 2003) por Javier Barnes y otros, en la que, siguiendo la presentación de la obra al español "se ocupa de la ciencia del Derecho administrativo en los albores del siglo XXI" (p. XVIII). Recibido el 10 de diciembre de 2018 y aceptado el 11 de abril de 2019.
} 
["Publicum ius est quod ad statum rei Romanae spectat, privatum quod ad singulorum utilitatem.]"

\section{Introducción}

Con esta distinción entre los dos regímenes jurídicos, formulada al inicio del Corpus luris (Inst. 1, 1, 4 y D. 1, 1, 2), el pensamiento romano ha impreso una huella irrepetible en los sistemas jurídicos de los pueblos ${ }^{1}$. El dualismo de Derecho Público y Privado ha ejercido una fuerza determinante sobre todo el globo: caracteriza las grandes codificaciones del Derecho Civil y del procedimiento administrativo; influencia los sistemas de justicia de muchos Estados que, junto a los jueces ordinarios, han instituido jueces administrativos; se manifiesta aun hoy en las articulaciones disciplinarias de las facultades de jurisprudencia y en las creaciones de cátedras y de estudios de investigación.

Ciertamente, los textos clásicos no se referían a una separación categórica. Los romanos no entendieron con esto poner en discusión la unidad de su ordenamiento jurídico ${ }^{2}$ y tampoco nosotros pensamos en esto. Todavía, tanto hoy como entonces, tiene sentido distinguir los dos segmentos del ordenamiento jurídico. A continuación, me gustaría ante todo delinear el marco conceptual de esta distinción (I y II), para después afrontar algunas cuestiones actuales referentes a la relación de la administración con el Derecho privado (III-IV).

\section{I. [Marco conceptual de la distinción, 1]}

\section{La res pública}

El concepto de statum rei Romanae se equipara a res publica. Es el Derecho Público quien se ocupa de esta ${ }^{3}$. La res publica se presenta ante nosotros en una doble forma: representa, en primer lugar, un fin conectado al bien común y, en segundo lugar, una específica organización del poder. Por ende, ella necesita de acciones promocionales pero también de límites. Se puede hablar de una "doble tarea": por una parte, hacer eficaz el poder estatal y, por otra,

\footnotetext{
*** Corpus luris Civilis, texto y traducción publicados por O. Behrends, R. Knütel, B. Kupisch, y h. h. Seiler, Vol. 2, 1995: Digesten, 1, 1, 2; Institutionen, 1.1.4. [Trad.: "Es derecho público el que se refiere al estado de la cosa romana; privado el que pertenece a la utilidad de cada cual"].

1 En cuanto a los diversos matices de significado del concepto ius publicum, desde el fin de la República, y a la evolución y difusión del mismo durante el periodo imperial, cfr. WIEACKER 1998, 29 I 2. En cuanto al significado actual de la distinción en el Derecho alemán cfr. BURGI 2006 en Hoffmann-Riem W. / Schmidt-Abmann E. / Vobkuhle A. (editores); en el Derecho italiano Cerulli Irelli 2011, 1 y ss.; CLARICH 2017, 46 y ss.; desde un punto de vista comparativo Napolitano 2003, 1 y ss. 2 En tal sentido KASER 1995, 175: "Los romanos no consideraron sacrificar la unidad del ordenamiento jurídico, contraponiendo el Derecho privado al Derecho común".

3 Al respecto, véase Zoller 2008, 3: "El concepto de res publica es la raison d'être del Derecho público".
} 
disciplinar puntualmente el ejercicio. En el Derecho Público y especialmente en el administrativo, se trata exactamente de esto.

El poder estatal es un poder donde se deposita confianza ${ }^{4}$, por lo que en el estado constitucional tiene valor en consecuencia el principio de la asimetría entre la libertad y la atribución (Kompetenza). Mientras el ciudadano actúa en el ejercicio de sus libertades elementales, el Estado actúa, en cambio, en el ejercicio de sus atribuciones legales. Esta evidente asimetría no está limitada al Estado nacional, pero se puede observar también cuando organizaciones internacionales ejercen un poder público ("public authority")b. En una determinada fase de su desarrollo, el Derecho Público ha resultado estrechamente conectarlo con la idea de Estado nacional ${ }^{7}$. Esto no se encuentra todavía circunscrito a los estados nacionales, pero cumple un rol específico cuando se trata de disciplinar jurídicamente un poder soberano.

Las autoridades públicas no tienen ninguna libertad, pero sí tienen atribuciones, las que le son asignadas por el Derecho (constituciones, leyes, tratados internacionales). Las atribuciones tienen una doble naturaleza: autorizan a actuar unilateralmente, a decidir según el principio de mayoría y eventualmente a imponer las decisiones con medios coercitivos. Sin embargo, las atribuciones pueden ser ejercitadas solo dentro de su propio marco jurídico y deben ser justificadas, desde el punto de vista finalista, en relación a la prosecución del bien común. La elaboración jurídica de este último constituye el núcleo fundante del Derecho Público.

\section{2. ¡Es muy distinto el Derecho Privado!}

El eje del Derecho Privado está constituido por elecciones libres de sujetos jurídicos en posición de igualdad. A estos se les debe asegurar un marco jurídico de confianza. El contenido de estas relaciones, a su vez, queda confiada fundamental a la autonomía privada. En contraposición a la doble naturaleza de las atribuciones, la libertad posee una naturaleza simple. Los individuos mismos regulan sus propios intereses y los expresan autónomamente. Ellos no deben motivar sus conductas, ciertamente no pueden producir unilateralmente efectos jurídicos, sino solo consensualmente. Como regla, no son necesarias especiales autorizaciones o garantías procesales, como aquellas que pertenecen a los estándares del Derecho público. El Derecho privado delinea límites externos. En esto reside su especial flexibilidad y ubicuidad.

\footnotetext{
4 Al respecto, véase la Decisión de la Corte Federal Constitucional Alemana 128, 222, 244 y ss.

5 Al respecto, véase SchmidT-Assmann 2004, 16 y ss. y 284 y ss.

6 Al respecto, véase von Bogdandy A. / Wolfrum R. / von Bernsdorf J. / Dann P. / Goldmann M. (editores) 2010, 659 y ss.

7 CAssese 2010, 41; Zoller 2008, 25 y ss. (Comparación de los desarrollos en Francia, Alemania, Inglaterra y en los Estados Unidos).
} 


\section{II. [Marco conceptual de la distinción, 2]}

En los ordenamientos constitucionales que distinguen entre la libertad civil y vínculo estatal y que se fundan sobre la necesaria legitimación de cada acción estatal, es normal expresar las distintas tipologías de intereses con dos distintos regímenes jurídicos. El dualismo no representa, sin embargo, un a priori. Como concepto esto resulta plausible, porque intenta recoger en dos modelos de regulación -que son a sabiendas y sistemáticamente estructurados de distinto modo- las cuestiones relativas a la legitimación y al bien común que se plantean la sociedad y el Estado. Respecto del ejercicio del poder estatal, no podemos estar satisfechos con que el Derecho ponga solo algunos límites extrínsecos. La necesidad de motivación conduce sobre todo a utilizar estructuras jurídicas específicas que alcanzan el ámbito interno del proceso decisional mucho más en profundidad que en el caso del Derecho Privado, en que existe una especie de "marco" en el ámbito del cual la actividad privada se desarrolla libremente.

El dualismo no se pone en duda por el hecho que hoy Estado y sociedad, administración y economía, cooperan en modos multiformes. Al contrario: si el "Estado cooperativo" no debe traducirse en un desorden general y no se debe empañar la responsabilidad democrática de los órganos estatales, entonces es necesaria una clara diferenciación de las distintas racionalidades de acción de los socios que colaboran. Los organismos estatales no pueden deshacerse de sus vínculos, poniéndose al mismo nivel de los privados. Estos quedan sometidos a las prescripciones constitucionales aun cuando utilizan formas contractuales. La forma puede también ser la del Derecho Privado,, sin embargo, el vínculo permanece. Esta conclusión se puede formular en modo más claro en un contexto de dualismo conceptual que en uno de monismo.

La referencia al monismo de los países del common law no constituye en cada caso un argumento contra el dualismo. Está fuera de discusión que, indistintamente de cuánto sugieren el Derecho romano y las tradiciones continentales, un orden jurídico puede ser construido en forma monista. Sin embargo, si se observa atentamente, se comprende que incluso en los contextos monistas se debe poner atención a la distinción entre libertad y atribución. Esto constituye un legado hereditario del estado constitucional del Atlántico ${ }^{8}$. Cito a este propósito la Corte Suprema de los Estados Unidos en la decisión Lebron v. Amtrak: "It surely cannot be that government, state or federal, is able to evade the most solemn obligations imposed in the Constitution by simply resorting to the corporate form" .

\footnotetext{
8 Al respecto, Zoller 2008, 1: "Independientemente de su diversidad, todos los sistemas jurídicos toman en cuenta, en un modo u otro, la necesaria distinción entre el Derecho público y privado". Cfr. también Loughuin 2003 (con una insistente defensa de la autonomía del Derecho público).

9513 U.S. 374, 397 (1995) National Lebron v. Railroad Passenger Corporation (Amtrak). [Trad.: Si se trata de un gobierno, estatal o federal, se pueden evadir las obligaciones más solemnes consagradas en la Constitución simplemente recurriendo simplemente a formas corporativas.]
} 
Con palabras casi idénticas se ha expresado la Corte constitucional federal alemana en la decisión Fraport ${ }^{10}$.

Han transcurrido ampliamente los tiempos en los cuales la acción estatal podía ser gestionada jurídicamente con pocas "prerrogativas" y en cuanto al resto recurriendo al common law. También, en los Países de Derecho anglo-americano existe hoy un Derecho Administrativo que -sin perjuicio del sistema jurisdiccional monista- refleja unos especiales vínculos y las especiales atribuciones del Government ${ }^{11}$. Las preguntas que en la sistemática continental representan las preguntas centrales del Derecho Público, allá son tratadas como áreas problemáticas singulares y como temas específicos del ordenamiento monista. En este sentido, la diferencia entre civil law y common law no tiene que ser entonces exagerada ${ }^{12}$. La concepción dualista, seguida en la mayor parte de los Estados europeos, facilita la reflexión sistemática, porque ofrece a todas las reglas particulares relativas a la acción estatal un marco conceptual unitario y un único punto de referencia con la orientación a la res publica.

\section{III. [Cuestiones actuales referentes a la relación de la administración con el Derecho privado, 1]}

El dualismo continental debe recurrir también naturalmente a otras diferenciaciones. Esto es de inmediata evidencia cuando se deben ordenar las variadas formas de acción y de organización de la administración en el campo en el cual se coordinan el Derecho Público y aquello que es privado ${ }^{13}$. Aquí entran en juego los puntos de vista de la práctica administrativa que tienen su legitimidad en un Derecho Administrativo orientado a la práctica, sin que se ponga en duda la diferencia entre libertad y atribución.

El punto de partida es claro: cuando la administración dispone unilateralmente, es decir, desea actuar ejerciendo su imperio, lo puede hacer solo utilizando el Derecho Público. Para este fin ésta tiene a disposición los instrumentos del acto administrativo y de la coacción administrativa, así como las posibilidades ofrecidas de la estandarización administrativa (regulaciones, estatutos, prescripciones administrativas). En el Derecho de la organización también las instituciones y los entes de Derecho público deben asegurar un proceso decisional democrático. Estas formas de acción constituyen el corazón del Derecho Administrativo cuya relevancia y efectividad es demostrada diariamente por cientos de millones de decisiones (tasaciones fiscales, decisiones sobre demandas de pensión, autorizaciones de edificación y comerciales, reconocimiento de requerimientos de asilo, disposiciones de policía y de

\footnotetext{
10 Decisión de la Corte Federal Constitucional Alemana 128, 226 (245).

11 Cfr. D'Alberti 1992.

12 Igualmente Della Cananea 2005, 96 y ss.

13 Cfr. De Pretis 2014, 77 y ss.
} 
las autoridades de regulación), en las cuales se desarrolla la actividad administrativa de Derecho Público.

La administración no se encuentra limitada a recurrir al poder de imperio: ésta debe planificar, confrontarse, incentivar la actividad privada y reaccionar ante nuevas situaciones; coopera con los privados y participa en empresas privadas ${ }^{14}$. La tarea de promover el bien común -la res publica- presenta muchas facetas ${ }^{15}$. El Derecho Público no ofrece instrumentos adecuados para todas las tipologías de actividad. Para evitar condenar a la administración a permanecer inactiva o confinarla en la zona gris de la acción informal, se le debe permitir utilizar los instrumentos del Derecho Privado.

La mayor parte de los ordenamientos jurídicos lo permiten en un modo más o menos amplio, a veces contra su voluntad ${ }^{16}$. Sobre la administración organizada y operante según los módulos del Derecho Público, hay sectores en los cuales la administración utiliza las formas del Derecho Privado. En Alemania se trata de sectores importantes, incluyendo también la ley de contratación. En Italia tales ámbitos son más limitados, sin embargo, también en ese país la administración tiene la facultad de sacar provecho del Derecho Privado.

Frecuentemente la alternativa entre régimen público o privado es reconducida a una "libertad de elección" de la administración. Esto puede generar algún malentendido: en un Estado constitucional la administración no goza de alguna libertad "civil", se requiere elegir los instrumentos más adecuados sobre la base de un juicio ponderado de naturaleza discrecional ${ }^{17}$. Consecuentemente, la administración no está legitimada a "refugiarse" en el Derecho Privado con el objetivo de eludir disposiciones imperativas de carácter público.

Sí deberíamos, sin embargo, ser cautos en condenar el uso del Derecho Privado como si fuese algo patológico. El uso del Derecho privado puede involucrar consecuencias peligrosas para el Estado de Derecho. Sin embargo, también el uso de las formas del Derecho Público puede involucrar análogas consecuencias. La tarea del Derecho Administrativo es individuar las situaciones de peligro que se configuran en algunas ocasiones, de analizarlas y de desarrollar medidas capaces de contrarrestarlas. En sustancia esto significa: un Derecho administrativo moderno no puede ser limitado al Derecho Público. Se trata del "Derecho de la administración" en sentido amplio, que incluye también el Derecho Privado en el cual se avala la administración ${ }^{18}$.

\footnotetext{
14 Ha sido siempre así y esto no es una consecuencia de las privatizaciones de los últimos decenios. Las recientes privatizaciones han sin embargo contribuido a aumentar la intensidad de la cooperación. Claro en tal sentido Moliterni 2016, 50 y ss.

15 Cfr. Cerulli Irelli 2011, 87 y ss.; D’Alberti 2013, 163 y ss..

16 Resulta evidente en tal sentido la relación sobre Italia de MATTARELLA, 38 y ss.

17 Las personas jurídicas de Derecho Público (el Estado y sus articulaciones: Estados federales, Regiones, Comunas) no son, en principio, titulares de Derechos fundamentales; a tal propósito, renombrando a la Convención europea sobre los Derechos del hombre. RöBEN 2013.

18 BURG 2006 dice: "El Derecho público y el Derecho privado son regímenes de Derecho de los que se nutre el Derecho de la administración": a una conclusión análoga llega CerulLi IRELLI 2011,
} 
Quienes definen el Derecho Administrativo de modo tradicional solamente como un Derecho imperativo y lo consideran expresión de la soberanía del Estado, temerán probablemente una pérdida de identidad o aún una capitulación del "buen Derecho Administrativo". No atribuyo valor alguno a estas previsiones de posibles pérdidas o capitulaciones. En el desarrollo del Derecho Administrativo no debemos consentir la antigua mitología: no estamos pasando de la edad de oro a la edad del hierro. ¡Al contrario! Hoy estamos mucho más atentos y más equipados, respecto a las épocas precedentes, para afrontar nuevos retos. No le doy importancia a estos escenarios de disminución que conducen, bajo un perfil didáctico, hacia una dirección errada. ¿Qué estudiante podrá interesarse por una materia la cual los expertos afirman que está en riesgo de decadencia? Tenemos la tarea de motivar positivamente a nuestros estudiantes. El Derecho Administrativo (a diferencia de otros grupos de lobby) no tiene el apoyo de fuerzas políticas influyentes. Sin embargo, si queremos contribuir a la reforma del Estado y de la administración, debemos hacerlo formando estudiantes motivados, que estén convencidos de la relevancia de la materia y logren transportar tal convicción a su futura actividad profesional.

\section{IV. [Cuestiones actuales referentes a la relación de la administración con el Derecho Privado, 2]}

Aun subsistiendo buenos motivos para consentir a la administración, la utilización, aunque limitada, del Derecho Privado debe, sin embargo, garantizarse que sean respetados los estándares elementales de una administración democrática en un Estado de Derecho. Se trata de un difícil ejercicio de equilibrio que no puede llevar a la usurpación de libertades fundamentales por parte de la administración. Tal proceso no puede, sin embargo, igualmente conducir a una completa distorsión del Derecho Privado por obra de vínculos de carácter público; esto reduciría la flexibilidad tan deseada. En casos dudosos, los vínculos públicos deben prevalecer, en cuanto a la utilización del Derecho Privado por parte de la administración representa solamente una técnica de reglamentación que va interpretada en modo estructural, no sustancial.

Para la realización práctica de estas tareas pueden ser propuestas una pluralidad de construcciones. Resulta obligado discutir en tal sede, al menos, tres de éstas:

1. Se puede anteponer a la utilización del Derecho Privado una proporción de Derecho público. Tal construcción encuentra su fundamento en la teoría de los "actes détachables" [actos separables] o "dei due livelli" [de dos niveles] ${ }^{19}$. Las preguntas más importantes, en lo concerniente al perfeccionamiento de la relación jurídica, se resuelven en el primer nivel en el sen-

239 y ss.. En el sentido contrario evidenciando la autonomía del Derecho administrativo respecto al Derecho privado CLARICH 2017, 47 y ss..

19 En cuanto a la Italia Cerulu Irelu 2011, 116.; en cuanto a Alemania Schmidt-Assmann 2004, 290 y ss. 
tido del Derecho Público. Las preguntas más técnicas en relación a la ejecución pueden luego ser resueltas en el segundo nivel con los instrumentos del Derecho Privado. En tal sentido, en estas materias viene asegurada la influencia de los jueces administrativos, de los que se espera un conocimiento en el sector del Derecho Público. Por otra parte, supone una circunstancia negativa que una acción jurídica unitaria sea impedida, circunstancia que puede levantar consecuentes dificultades de delimitación de los respectivos niveles.

2. Tales dificultades son evitadas por una segunda construcción, que en Alemania se ha denominado "Derecho privado de la administración" (Verwaltungsprivatrecht) $^{20}$. La acción jurídica queda sujeta en su totalidad al Derecho privado y recae en la jurisdicción de los jueces civiles, considerados competentes y dotados de la necesaria experiencia para asegurar también el respeto de las particulares exigencias de tutela requeridas por el Derecho Público (principio de equivalencia de las vías jurisdiccionales) ${ }^{21}$. Estas exigencias de tutela son permitidas, por un lado, por la aplicación en vía analógica de la ley de procedimiento administrativo: imparcialidad, corrección procesal y transparencia, los que son válidos también cuando la administración se ampara en el Derecho Privado. Lo mismo pasa con las restricciones relativas a los Derechos fundamentales y a las obligaciones de paridad de tratamiento, de proporcionalidad y de tutela la legítima confianza. La aplicación analógica deja naturalmente espacio a las necesarias exigencias de diferenciación. Los vínculos son particularmente rígidos en los casos en los cuales el Derecho Privado sea utilizado para realizar tareas de carácter público como, por ejemplo, la política territorial comunal, la compraventa de terrenos edificables y la concesión de subvenciones. En la hipótesis en la cual la administración sea uno de los tantos concurrentes sobre el mercado, los vínculos no son así de rígidos. En ningún caso la administración goza de una plena libertad contractual. Para el resto el "Derecho privado administrativo" representa un proyecto dogmático en vía de desarrollo que debe ser utilizado de un modo conscientemente flexible.

3. Una cuestión aparte muy complicada, sería la relativa al uso de formas organizadas de naturaleza privada, por ejemplo, en los casos en que la administración gestione las propias actividades constituyendo o participando en una sociedad por acciones. En estos casos se trata principalmente de garantizar la influencia decisional de la institución legitimada democráticamente. A tal propósito las típicas formas jurídicas de ley de la empresa privada y de la empresa no son propiamente adecuadas. El instrumento con el cual la administración viene inducida a respetar, también en tales ocasiones, las particularidades del Derecho público, es expresado en alemán con Einwirkungspflicht [obligación de influencia o de dirección] ${ }^{22}$. Si la administración quiere sacar

\footnotetext{
20 Schmidt-Assmann 2004, 291 y ss.

21 Sobre la concurrencia de los jueces civiles y administrativos cfr. ScHmidT- Assmann et al. 2016, 711-769.

22 Al respecto, H-H. TRUTE, 75 y ss.
} 
provecho de las formas administrativas del Derecho Privado, debe garantizarse que las decisiones de los órganos de las empresas sirvan a la res publica y que pueden ser controladas por los representantes de la misma res publica. Para este fin, la administración -si quiere emprender una joint-venture o una colaboración público-privada- requerirá la atribución de los derechos necesarios en los contratos sociales. Esto resulta más fácil en las sociedades de responsabilidad limitada que en las sociedades por acciones. Sin embargo, ni siquiera las sociedades por acciones son inmunes a tal obligación de influencia impuesto por la constitución. En el Derecho privado de la empresa, como en el Derecho privado contractual, se pueden implementar elementos fundamentales que aseguren la tutela de exigencias públicas. No se puede depositar mucha confianza en el legislador y en sus intentos de crear formas especiales de Derecho de sociedades. Es oportuno, más bien, confiar en lo dogmático, en la acción sinérgica de la jurisprudencia y de la ciencia jurídica la tarea de desarrollar tales formas.

\section{Quien bien distingue, bien juzga}

¡Volvemos una vez más al texto del Corpus luris! La frase citada al inicio de este escrito sobre la distinción entre las dos ramas del Derecho es precedida por otra frase anticipada. Esta dice (D.1,1,2): "Huius studii duae sunt positiones" [Dos son los aspectos de este estudio].

El contexto ayuda a aclarar que la distinción entre los dos sectores del Derecho ha sido pensada principalmente por los estudios jurídicos, de los cuales se habla también al inicio del primer libro del Digesto ${ }^{23}$. La distinción entre Derecho Público y Derecho Privado tiene, por lo tanto, una naturaleza sistemática y es el fruto de una reflexión teórica, no privada de importancia que representa una pregunta central para la comprensión del ordenamiento jurídico ${ }^{24}$.

"Bene iudicat qui distinguit" [quien bien distingue, bien juzga]. Las libertades de los ciudadanos y las atribuciones de los sujetos titulares de poder soberano tienen cada uno la propia disciplina jurídica. Ambos regímenes jurídicos del Derecho Público y del Derecho Privado reflejan sustancialmente tales principios. Su distinción no está obsoleta: era y es tarea de la dogmática del Derecho Administrativo moldearla y adecuarla a los nuevos desafíos ${ }^{25}$. Lo dogmático representa el foro de la reflexión sugerida por el Digesto y puede presumir de una larga y consolidada tradición en los ordenamientos continentales, como resultado de la actividad conjunta de la práctica y de la ciencia jurídica. También hoy esto amerita de nuestra confianza así como de nuestra creatividad; su tarea es poner siempre en equilibrio la componente

\footnotetext{
${ }^{23}$ Calzante E. Zoller 2008, 263: "En otros términos, en un origen la distinción entre Derecho público y privado era significativa solo a fines de estudio del Derecho".

24 RADBRUCH 1956, 228 menciona: "El carácter de un ordenamiento jurídico se revela en modo significativo como un Derecho público y el Derecho privado se colocan uno respecto al otro".

25 Schmidt-Assmann 2013; en tal punto de vista las opiniones de De Lucia et al. 2015.
} 
estática y aquella dinámica del Derecho. Esto vale también para la distinción entre Derecho Público y Derecho Privado. Su utilización es concreta y flexible y conoce, como se ha demostrado por el Derecho Privado de la administración, formas intermedias. Las coordenadas fundamentales resultan, aun hoy, firmes: "Publicum ius est quod ad statum rei Romanae spectat, privatum quod ad singulorum utilitatem" [Es derecho público el que se refiere al estado de la cosa romana; privado el que pertenece a la utilidad de cada cual].

\section{Bibliografía citada}

Burgi, M. (2006). Rechtsregime. Hoffmann-Riem, W., Schmidt-Abmann, E., Vobkuhle, A. [eds.], Grundlagen des Verwaltungsrechts, Vol. 1, $2^{\text {a }}$ edición, 1 y ss;

CASSESE, S. (2010). Die Entfaltung des Verwaltungsstabes in Europa. Von Bogdandy A., Cassese, S., Huber, P.M. [eds.], Ius Publicum Europaeum-IPE-, Vol. 3, pp. 1-68.

CASSESE, Sabino (2015). Un nuevo corso del diritto amministrativo?. Rivista Trimestrale di Diritto Publicco, No 1, pp. 25-27.

Cerulti Irelui V. (2011). Amministrazione Pubblica e diritto privato. Torinio: G. Giappichelli Editore, $288 \mathrm{pp}$.

Clarich, M. (2017). Manuale di diritto amministrativo. II Mulino, 521 pp.

De Lucia, Luca (2015). II diritto amministrativo tedesco e il rinnovamento della dogmatica giuridica. Rivista Trimestrale di Diritto Publicco No 1, pp. 1-8.

De Pretis, Daria (2015). Una dogmatica "riformata" del diritto amministrativo. Rivista Trimestrale di Diritto Publicco No 1, pp. 9-16.

De Pretis, D. (2014). Die Entfaltung des Verwaltungsstabes in Europa. Von Bogdandy A., Cassesse S., P.M. Huber [eds.], Hanbuch Publicum Europaeum. IPE, pp. 77 y ss.

Della Cananea, G. (2005). Public Law Disputes in a unified Europe. Italian Journal of Public Law, Vol.7, No 1 , pp. 96 y ss.

KASER, Max (1955). Das römische Privatrecht. C.H. Beck, 651 pp.

Loughuin, Martin (2003). The Idea of Public Law. Oxford, University, 188 pp.

MerusI, Fabio (2015). Divagazioni su di una pretesa nuova dogmatica nel diritto amministrativo. Rivista Trimestrale di Diritto Publicco, No 1, pp. 17-23.

MoliternI, A. (2016). Amministrazione consensuale e diritto privato. Napoli: Jovene Editore, $487 \mathrm{pp}$.

Napolitano, Giulio (2003). Pubblico e Privato nel Diritto Amministrativo. Milano: Dott. A. Giuffré Editore, 262 pp.

B.G. Mattarella (2015). Die Entfaltung des Verwaltungsstabes in Europa. Von Bogdandy A., Cassesse S., P.M. Huber [eds.], Hanbuch Publicum Europaeum (nota $N^{\circ}$ 8), IPE Bd. 3, 45 $\mathrm{N}^{\circ} 38$ y ss.

RADBRUCH, Gustav (1956). Rechtsphilosophie. Alemania: Stuttgart, 5a edición, 391 pp.

RÖBEN, V. (2013). Kapitel 5: Grundrechtsberechtigle und -verpflichtete, Grundrechtsgeltung. Dorr O., Grote R., T. Marauhn [eds.], EMRK/GG Konkordanzkommentar, $2^{\text {a }}$ ed., vol. 1 cap. $5, N^{\circ} 48$ y 59 , pp. 253-286.

SchmidT-Assmann, Eberhard (2004). Das Allgemeine Verwaltungsrecht als Ordnungsidee. Alemania: Springer, $2^{a}$ Edición, 470 pp.

SCHMidT-AssmanN, Eberhard (2013). Verwaltungsrechtliche Dogmatik. Tübingen: Mohr Siebeck, 192 pp.

Schmidt-Assmann, Eberhard, De Lucia, Luca, Romano, Maria Chiara (2016). Prospettive della tutela giurisdizionale amministrativa in Germania e in Italia. Diritto Processuale Amministrativo, $N^{\circ} 3$, pp. 711-769.

H-H. Trute, en Rechtsregime. Hoffmann-Riem, W., Schmidt-Abmann, E., Vobkuhle, A. [eds.], Grundlagen des Verwaltungsrechts, Vol. 1, $2^{\mathrm{a}}$ edición (nota al pie No 2) $6 \mathrm{~N}^{\circ} 75$ y ss.

Von Bogdandy, Armin, Wolfrum, Rüdiger, Von Bernsdorf, Jochen, Dann, Philipp, Goldmann, Matthias [eds.] (2010). The Excercise of Public Authority by International Institutions. Heidelberg: Springer, $1008 \mathrm{pp}$. 
WIEACKER, Franz (2006). Römische Rechtsgeschichte. Müncher: Beck, 474 pp.

Zöller, Elisabeth (2008). Introduction to Public Law: A comparative Study. United States of America: Martinus Nijhoff Publishers, 290 pp.

\section{Normas citadas}

Constitución Federal Alemana (Grundgesetz die Bundesrepublik Deutschland), 1949.

\section{Jurisprudencia citada}

Decisión de la Corte Federal Constitucional Alemana 128, 226, pp. 244 y ss. 